Tropical Journal of Pharmaceutical Research May 2015; 14(5): 753-760

ISSN: $1596-5996$ (print); 1596-9827 (electronic)

(C) Pharmacotherapy Group, Faculty of Pharmacy, University of Benin, Benin City, 300001 Nigeria.

All rights reserved.

Available online at http://www.tjpr.org

Original Research Article

http://dx.doi.org/10.4314/tjpr.v14i5.2

\title{
Formulation and Characterization of Biodegradable Medicated Chewing Gum Delivery System for Motion Sickness using Corn Zein as Gum Former
}

\author{
Farhad Firoze Mehta* and Piyush Trivedi \\ Department of Pharmaceutics, School of Pharmaceutical Sciences, Rajiv Gandhi Technological University, Bhopal (M.P.), India
}

*For correspondence: Email: mehta.farhad@gmail.com; Tel: +91-9893055516

Received: 5 August 2014

Revised accepted: 16 March 2015

\begin{abstract}
Purpose: To formulate and evaluate biodegradable corn zein as a base for diphenhydramine hydrochloride medicated chewing gum for effective management of motion sickness.

Method: Corn zein gum formulations were prepared using a fixed concentration (35\% w/w) of different plasticizer for each formulation. Substances used as plasticizer were triacetin, oleic acid, polyethylene glycol (PEG)-600, tributyl citrate, PEG-200, PEG-300, PEG-400, PEG-4000, triethyl citrate and castor oil. The gum formulations were characterized for the following parameters: texture profile analysis (TPA), biodegradation, in vitro drug release using a modified chewing apparatus, and sensory properties.

Result: Formulations code MCG-5 and MCG-9 which incorporated glyceryl triacetate and castor oil as plasticizers, respectively, showed a biodegradation score of 2 and 1, respectively, indicating significant biodegradation. The formulation with castor oil as plasticizer showed hardness, gumminess, chewiness, and cohesiveness of $4228.87 \mathrm{~g}, 1002.52,360.06 \mathrm{~g}$ and 0.237 ; these values are similar to that of the reference, Superpep ${ }^{\circledR}$ travel chewing gum. In vitro drug release of the drug was $95 \%$, and showed uniform distribution of the drug in the gum matrix.

Conclusion: Corn zein is suitable for use as a biodegradable gum base for the delivery of diphenhydramine hydrochloride, and can be developed as an alternative to currently used gum bases for commercial products.
\end{abstract}

Keywords: Corn zein, Chewing gum delivery system, Motion sickness, Biodegradation, Texture profile analysis, Sensory evaluation

Tropical Journal of Pharmaceutical Research is indexed by Science Citation Index (SciSearch), Scopus, International Pharmaceutical Abstract, Chemical Abstracts, Embase, Index Copernicus, EBSCO, African Index Medicus, JournalSeek, Journal Citation Reports/Science Edition, Directory of Open Access Journals (DOAJ), African Journal Online, Bioline International, Open-J-Gate and Pharmacy Abstracts

\section{INTRODUCTION}

Chewing gum is an attractive drug delivery system for several reasons. It is easy to administer and requires no water, carries a pleasant taste, and is acceptable to children. Drug action is fast as active substances are absorbed through the permeable, blood-rich oral mucosa and pass by the jugular veins directly into the blood circulation system [1]. Chewing gum as a drug delivery system offers convenience in the treatment [2], and prevention of motion sickness and nausea. Medicated chewing gum (MCG) is also a useful delivery system for agents intended for systemic delivery [3].

Zein is a water-insoluble prolamine derived from corn gluten and manufactured initially as a concentrated powder. Diphenhydramine 
hydrochloride, based on its higher salivary solubility and fewer side effects (no extra pyramidal effect), is a suitable candidate for the formulation of MCG for the prevention of motion sickness.

The utilization of corn zein in a chewing gum base has been investigated by Mc Gowan et al. [4]. In the study, formulations containing corn zein with different types of plasticizing agents were compared using time-intensity (TI) method for sensory evaluation. It was found that plasticizers not only affected the texture of the resulting gums but also their taste and aroma. Zein has been investigated for uses in industry as a raw material for film coatings, adhesives, and plastic applications [5-8]. Since zein films are completely safe to ingest, it is a perfect coating for foods $[9,10]$ and pharmaceutical ingredients.

The objective of the present work was to formulate and evaluate corn zein biodegradable medicated chewing gum of diphenhydramine hydrochloride for the effective management of motion sickness.

\section{EXPERIMENTAL}

\section{Ingredients for preparation of gum sample}

The ingredients used in making the chewing gums include corn zein, which was used as bulking agent (regular grade powder form), purchased from M.P. Biomedical Private Limited, India; distilled monoglyceride, which was used as a emulsifier and available in liquid form (DMG, Estelle Private Limited Maharashtra, India); partially hydrogenated palm oil, which was used to increase consistency, shelf life and was available in liquid form (a gift from Krishna Oil Extraction Limited, Rajgarh, (M.P.), India. Artificial orange flavor, which was available as solid granules (Glee Gum Kit, USA), photoactive titanium dioxide, which was used as a filler and was available as solid flakes (Smart Nanoz Private Limited, Pune, Maharashtra, India); Triacetin, oleic acid, PEG-600, tributyl citrate, PEG-200, PEG-300, PEG-400, triethyl citrate, castor oil were used as plasticizers and were available in liquid form. PEG-4000 was used as a plasticizer and was available as solid flakes. Sorbitol and mannitol are sugar alcohol, which were used as sweetener and available in solid powder form; gum acacia was used as a binder and was available in solid powder form, titanium dioxide was used as an opacifier and was available as crystalline solid. Glycerin was used as a softener and was available in liquid form and polysorbate-60 was used as emulsifier and was available in liquid form (purchased from C.D.H., New Delhi, India). Ace K was available as white crystalline powder as a gift sample from (Triveni Chemicals Vapi, Gujarat, India) and erythritol was available in crystalline powder as a gift sample from (Herboveda India Noida, (U.P.) and was used as artificial sweetener. All the ingredients used in the gum formulation were of food-grade quality and of LR (laboratory reagent) grade.

\section{Preparation of corn zein chewing gum}

A modified method suggested by McGowan et al [4] was used for the preparation of corn zein chewing gum. Laboratory sigma blade mixer (model LPSM-1kg, Prism Pharma Machinery Vatva Gujrat, India) with front to rear speed ratio of 2:1 was used for formulation of corn zein chewing gum. Aqueous-ethanol $(70 \% \mathrm{v} / \mathrm{v})$ solution of zein powder was added to sigma blade mixer. All the ingredients except hydrogenated palm oil and flavor were added and blended in the mixer for $10 \mathrm{~min}$. Various formulations of corn zein chewing gum samples were prepared varying only the plasticizer (MCG1 to MCG-10, as shown in Table 1). The special (z) shapes of blade present in sigma blender ensured complete mixing and produced heat, which evaporated the ethanol present in the solution. To prevent exposure to heat, partially hydrogenated vegetable palm oil was added to the blender. Corn zein solution was poured into the container with five liters of purified ice water maintained at $3^{\circ} \mathrm{C}$. The cold water caused zein to precipitate from ethanol solution, forming a dough-like consistency. Zein particles aggregated together and entrapped the rest of the ingredients. The dough was mixed, and rinsed with purified water twice for $10 \mathrm{~min}$ on each occasion to form a flexible gum base. The kneading action of the blender further blended the ingredients and eliminated residual ethanol. The gum base was then spread into a thin sheet with a roller and cut into strips of $5 \mathrm{~g}$ each. The gum samples were stored at room temperature.

\section{Coating of corn zein formulations}

Corn zein chewing gum was coated with a solution of sweetener and glycerin. This mixture was heated at $60{ }^{\circ} \mathrm{C}$ for $15 \mathrm{~min}$ and allowed to mix uniformly. Gum pieces were dipped in the solution for 1 minute to allow the liquid to spread evenly over the piece. A dry powder sweetener was applied to dry the liquid coating; and is referred to as dry charging [11] in soft panning operation. The drug (diphenhydramine hydrochloride, $10 \mathrm{mg}$ ) was pre-blended with dry charge material and orange flavor. 
Table 1: Composition of corn zein gum formulation

\begin{tabular}{|c|c|c|c|c|c|c|c|c|c|c|}
\hline $\begin{array}{l}\text { Ingredient } \\
(\% \text { w/w) }\end{array}$ & MCG-1 & MCG- 2 & MCG- 3 & MCG- 4 & MCG -5 & MCG -6 & MCG- 7 & MCG- 8 & MCG -9 & MCG- 10 \\
\hline Corn zein & 50 & 50 & 50 & 50 & 50 & 50 & 50 & 50 & 50 & 50 \\
\hline $\begin{array}{l}\text { Distilled mono } \\
\text { glyceride }\end{array}$ & 2 & 2 & 2 & 2 & 2 & 2 & 2 & 2 & 2 & 2 \\
\hline $\begin{array}{l}\text { Palm-oil } \\
\text { partially } \\
\text { hydrogenated }\end{array}$ & 8 & 8 & 8 & 8 & 8 & 8 & 8 & 8 & 8 & 8 \\
\hline Plasticizer* & H35 & E35 & F35 & G35 & A35 & D35 & B35 & C35 & J35 & 135 \\
\hline $\begin{array}{l}\text { Photoactive } \\
\text { titanium dioxide }\end{array}$ & 5 & 5 & 5 & 5 & 5 & 5 & 5 & 5 & 5 & 5 \\
\hline
\end{tabular}

For coating of MCG six coating solutions were used, which varied in their sweetener concentration (1-6\% $\% / w)$, the flowchart in Figure 1 illustrates the components and preparation of the sweetener blend. During coating process for one dry charge application, two to four liquid applications were made to uniformly cover the dry charge material.

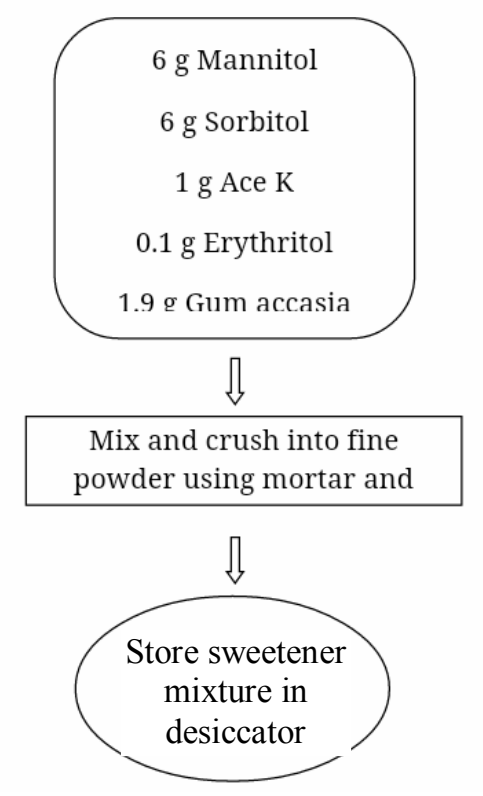

Figure 1: Flowchart for preparation of sweetener blend

The sweetener blend would help us in overcoming the bitterness of the drug component in MCG. The coating solution containing the sweetener was added to the surface of the gum by rolling pieces through the coating solution. Then the pieces were placed fully separated onto a glass dish and covered with plastic wrap and stored in the refrigerator.

\section{Coating firmness determination}

Firmness of the coating solution was determined with stable micro system model number TA.XT express enhanced texture analyzer. Results were recorded and evaluated using stable micro systems (U.K.) exponent light express software, version 5.1.1.1. The variables and parameters were calculated by macros written in the same software and the processing and evaluation of the data were done by MS office excel 2007 software.

\section{Characterization of corn zein chewing gum \\ Determination of texture profile analysis}

Texture profile analysis (TPA) is an objective method of sensory analysis for food samples that correlates well with sensory evaluation. The texture profile method was developed by the texture group at General Foods Corporation in 1963 for the quantitative analysis of food texture [12]. The test consists of compressing a bitesized piece of food twice in a reciprocating motion that imitates the action of the jaw and analyzing the textural parameters such as hardness, fracturability, springiness, cohesiveness, adhesiveness, gumminess, chewiness, and resilience from the force-time curve. Compression platen of $35 \mathrm{~mm}$ diameter probe $(P / 35)$ of different chewing gum samples were tested using texture analyzer and texture profile analysis (TPA).

\section{Biodegradation study for corn zein chewing gum}

The chewing gum bases were rolled out to form $2 \mathrm{~mm}$ thick slabs and were stuck onto metal plates (dimension $5 \times 25 \mathrm{~cm}$ ). Weathering was tested as described in U.S. Patent 7479293B2 
[13], which is similar to International Organization for Standardization (ISO) 4892, in which cycle of wetting was run for $2 \mathrm{~h}$ at $40^{\circ} \mathrm{C}$, alternated with 6 hours of illumination by UV bulb at $45^{\circ} \mathrm{C}$. The cycle was run until an illumination period of 2500 $\mathrm{h}$ was reached. The degradation of chewing gum base was accompanied by increased chalking on the surface. The chalking on the surface of the test slab was determined visually both before and after weathering. Chalking was qualitatively assessed on scale from a 1 to 6 , where 1 refers to severe chalking and 6 to no chalking.

\section{In vitro drug release}

In vitro drug release was tested using modified in vitro chewing apparatus. The machine was specially fabricated to mimic the effect of human chewing [14]. Figure 2 shows technical drawing of modified in vitro chewing machine. The apparatus has one chewing module. Chewing module consists of a stainless steel test cell in which two vertically oriented pistons holding an upper and lower chewing surfaces are mounted. The cell is filled with an appropriate test medium, usually $25-50 \mathrm{~mL}$ (as per European pharmacopeia section 01/2005:20925, descriptions for chewing chamber for medicated chewing gum) and the chewing gum is loaded onto the lower chewing surface. The chewing procedure consists of up and down strokes of the lower surface in combination with a twisting movement of the upper surface. This action provides mastication of the chewing gum and an adequate agitation of the test medium. The upper chewing surface is connected to a stand in a locked position but revolves on its axis when performing the twisting movement with the help of twisting motor. The test cell is connected to the lower chewing surface that is fixed against revolving movements during the up and down strokes. The movements of the pistons are driven by mechanical motor. The distance settings of the chewing surfaces, the frequency of the strokes, as well as the angle of the twisting movement are adjustable. The chewing surfaces, manufactured from acid-resistant stainless steel, are circular with a blasted surface to counteract gliding of the chewing gum. The upper chewing surface is parallel to the central part of the lower one. The whole upper chewing surface may be lowered during preparation, during sampling of the test medium and when emptying the cell after completion of the release test. Thermostat is achieved by use of a chamber in thermal contact with the lower surface.

\section{Sensory evaluation}

The potential commercialization of zein-based gum depends on the response of consumers. Sensory evaluation will identify critical attributes that must be kept in mind in product and process development. The sensory evaluation was undertaken to detect any variation produced in sensory attributes of corn zein chewing gum by incorporation of $1-6 \% \mathrm{w} / \mathrm{w}$ sweetener coating solution. The sensory evaluation was conducted in a quiet and well-lit room free from any odor. Panel booths were illuminated uniformly with special daylight bulbs for evaluation of color and appearance.

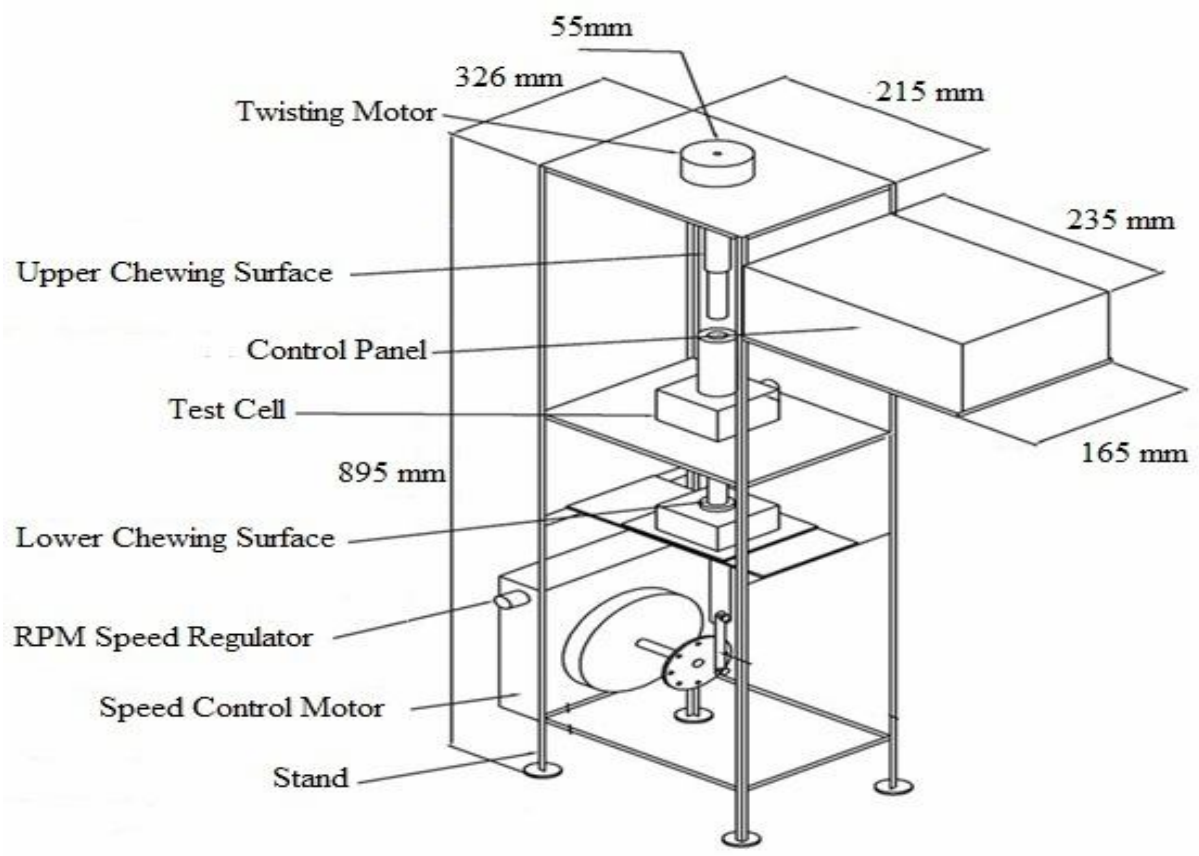

Figure 2: A sketch of the cross sectional view of in vitro chewing apparatus 
Nine panelist, six males, and three females were selected based on their sensitivity to determine sweetness, and were trained to identify and quantify the sensory characteristic of corn zein chewing gum. The sensory evaluation was carried out on the basis of a 9-point hedonic scale ranging from $9=$ like extremely to $1=$ dislike extremely by grading corn zein chewing gum with low calorie sweetener against a control with $6 \% \mathrm{w} / \mathrm{w}$ sucrose for sweetness, color and appearance, body and texture and overall acceptability [15].

\section{Statistical analysis}

Data were analyzed by one way analysis of variance (ANOVA) with a subsequent least significant difference test for multiple sample comparisons using sigma stat version-3.5, systat software Inc, Chicago, Illinois, USA. Level of statistical significance was fixed at 0.05.

\section{RESULTS}

\section{Coating firmness}

Coating firmness data for corn zein formulation (MCG-1 to MCG-10) with optimized $3 \%$ coating solution is summarized in Table 2.

\section{Texture profile analysis (TPA)}

TPA parameters of corn zein gum formulations (MCG1-MCG-10) are presented in Table 3 below. Reference standard for TPA determination was superpep travel chewing gum, from Hermes Arzeneimittel, Munich, Germany. Control standard chewing gum was chicza chewing gum from Mayan rainforest company limited, U.K.

Table 2: Coating firmness data $(\mathrm{Kg})$ for corn zein chewing gum using Texture Analyzer

\begin{tabular}{lcccccc}
\hline $\begin{array}{l}\text { Formulation } \\
\text { Code }\end{array}$ & $\begin{array}{l}\text { Coating-1 } \\
\text { firmness }\end{array}$ & $\begin{array}{l}\text { Coating-2 } \\
\text { firmness }\end{array}$ & $\begin{array}{c}\text { Coating-3 } \\
\text { firmness }\end{array}$ & $\begin{array}{c}\text { Coating-4 } \\
\text { firmness }\end{array}$ & $\begin{array}{c}\text { Coating-5 } \\
\text { firmness }\end{array}$ & $\begin{array}{c}\text { Coating-6 } \\
\text { firmness }\end{array}$ \\
\hline MCG-1 & 0.765 & 0.906 & 0.916 & 1.362 & 1.574 & 1.761 \\
MCG-2 & 0.888 & 0.920 & 1.197 & 1.250 & 1.383 & 1.797 \\
MCG-3 & 0.878 & 1.061 & 1.076 & 1.084 & 1.090 & 1.684 \\
MCG-4 & 0.886 & 0.922 & 1.194 & 1.299 & 1.374 & 1.462 \\
MCG-5 & 0.589 & 0.668 & 0.757 & 0.768 & 0.961 & 1.011 \\
MCG-6 & 0.801 & 0.859 & 0.954 & 1.050 & 1.399 & 1.428 \\
MCG-7 & 0.807 & 0.826 & 0.867 & 0.946 & 0.999 & 1.333 \\
MCG-8 & 0.832 & 1.020 & 1.053 & 1.198 & 1.235 & 1.401 \\
MCG-9 & 0.810 & 0.892 & 1.008 & 1.088 & 1.127 & 1.208 \\
MCG-10 & 0.729 & 0.790 & 0.880 & 0.970 & 1.361 & 1.562 \\
Avg. & 0.798 & 0.886 & 0.990 & 1.101 & 1.250 & 1.464 \\
S.D. & 0.092 & 0.111 & 0.143 & 0.181 & 0.199 & 0.247 \\
\hline
\end{tabular}

Table 3: TPA values for various corn zein formulations

\begin{tabular}{|c|c|c|c|c|c|c|c|}
\hline Test ID & $\begin{array}{l}\text { Hardness } \\
\text { (g) }\end{array}$ & $\begin{array}{c}\text { Adhesiveness } \\
\text { (g.sec) }\end{array}$ & Springiness* & Cohesiveness* & Gumminess\# & $\begin{array}{c}\text { Chewiness } \\
(\mathrm{g})\end{array}$ & Resilience* $^{*}$ \\
\hline TPA,MCG-1 & 3731.662 & - & 0.348 & 0.221 & 823.906 & 286.322 & 0.171 \\
\hline TPA,MCG-2 & 4143.839 & - & 0.356 & 0.253 & 1048.745 & 372.887 & 0.213 \\
\hline TPA,MCG-3 & 3750.523 & -0.095 & 0.360 & 0.225 & 844.839 & 303.899 & 0.187 \\
\hline TPA,MCG-4 & 4091.319 & - & 0.354 & 0.223 & 910.349 & 322.415 & 0.173 \\
\hline TPA,MCG-5 & 4029.165 & -0.003 & 0.361 & 0.225 & 905.749 & 326.563 & 0.177 \\
\hline TPA,MCG-6 & 4250.123 & - & 0.329 & 0.221 & 939.063 & 308.643 & 0.187 \\
\hline TPA,MCG-7 & 4164.589 & - & 0.319 & 0.225 & 936.190 & 298.495 & 0.195 \\
\hline TPA,MCG-8 & 4688.094 & - & 0.348 & 0.221 & 1040.635 & 361.960 & 0.201 \\
\hline TPA,MCG-9 & 4228.871 & - & 0.359 & 0.237 & 1002.524 & 360.061 & 0.202 \\
\hline TPA,MCG-10 & 3994.430 & - & 0.357 & 0.229 & 913.189 & 326.139 & 0.186 \\
\hline Coef.var & 0.066 & -1.315 & 0.041 & 0.044 & 0.080 & 0.090 & 1.397 \\
\hline S.D. & 271.746 & 0.065 & 0.014 & 0.010 & 75.322 & 29.401 & 0.077 \\
\hline Avg. & 4107.261 & -0.049 & 0.349 & 0.228 & 936.519 & 326.738 & 0.055 \\
\hline
\end{tabular}

*Springiness, cohesiveness, and resilience are in ratio, hence no unit; \#Gumminess is product of hardness and cohesiveness 


\section{Biodegradation of corn zein chewing gum}

Table 4 presents biodegradation study result for MCG-1 to MCG-10 formulations. The formulations MCG-5 and MCG-9 shows significant biodegradation with a chalk score of 2 and 1 respectively. MCG-5 contains glyceryl triacetate as plasticizer while MCG-9 contains castor oil as plasticizer.

Table 4: Biodegradation data for MCG-1 to MCG-10 formulations

\begin{tabular}{lcc}
\hline $\begin{array}{l}\text { Formulation } \\
\text { code }\end{array}$ & $\begin{array}{c}\text { Chalking } \\
\text { before } \\
\text { weathering }\end{array}$ & $\begin{array}{c}\text { Chalking } \\
\text { after weathering } \\
\text { (mean } \pm S D, \mathbf{n}=\mathbf{6} \text { ) }\end{array}$ \\
\hline MCG-1 & 6 & $3 \pm 0.10$ \\
MCG-2 & 6 & $5 \pm 0.18$ \\
MCG-3 & 6 & $3 \pm 0.12$ \\
MCG-4 & 6 & $4 \pm 0.17$ \\
MCG-5 & 6 & $2 \pm 0.12$ \\
MCG-6 & 6 & $4 \pm 0.11$ \\
MCG-7 & 6 & $3 \pm 0.12$ \\
MCG-8 & 6 & $5 \pm 0.13$ \\
MCG-9 & 6 & $1 \pm 0.04$ \\
MCG-10 & 6 & $3 \pm 0.12$ \\
\hline
\end{tabular}

\section{In vitro drug release}

Figure 3 shows diagrammatic sketch of drug release profile for MCG 1-10 formulations. Mean chewing time was $30 \mathrm{~m} \mathrm{[14].} \mathrm{During} \mathrm{that} \mathrm{time,}$ highest drug release (95\%) was observed in formulations MCG 5 and MCG -9 that used triacetin and castor oil as plasticizer respectively and the lowest drug release $(79 \%)$ was observed in MCG-1 formulation that used PEG 4000 as plasticizer. It was noted that during first $15 \mathrm{~m}$ of mastication MCG-9 formulation released $54 \%$ of drug.

\section{Sensory evaluation}

In terms of sweetness corn zein chewing gum coated with coating 3 resemble the control and possessed the same desirable sweetness. However, color and appearance, body and texture, and overall acceptability score were lower $(p<0.05)$ in corn zein chewing gum sweetened with low calorie sweetener as compared to the control with sucrose (Table 5).

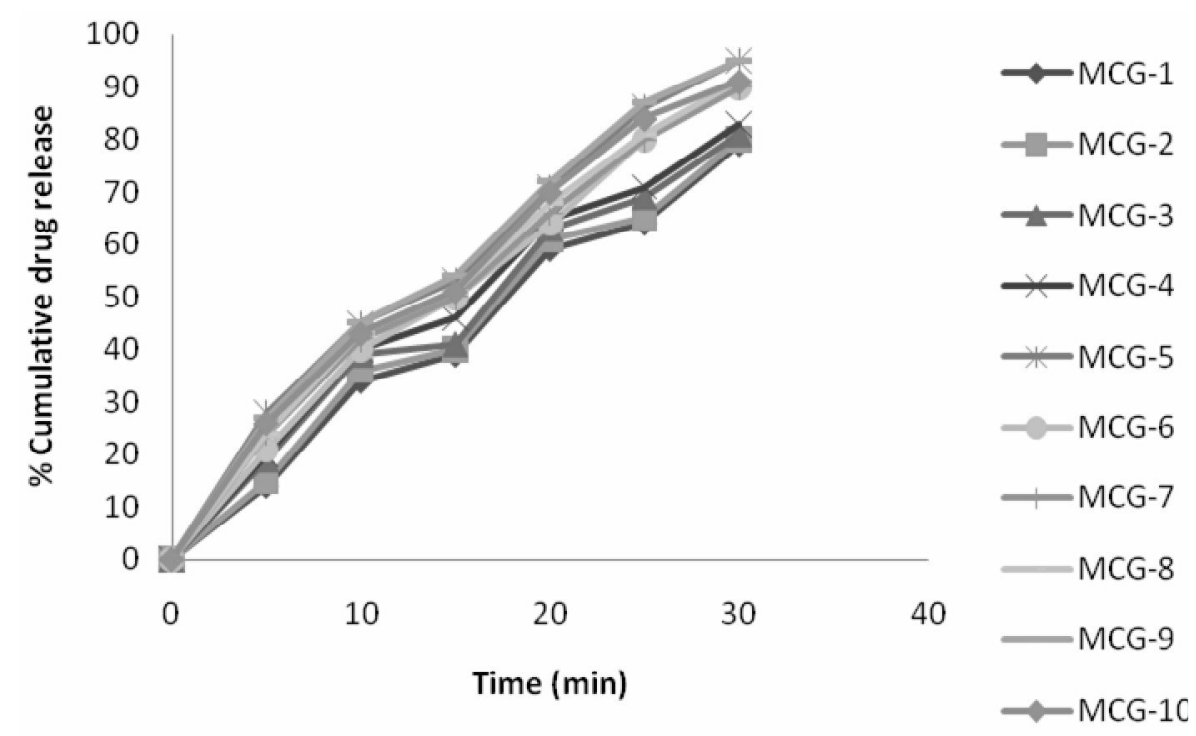

Figure 3: Drug release profile of MCG formulations

Table 5: Sensory evaluation of corn zein chewing gum

\begin{tabular}{lccccccc}
\hline Characteristic & Control & Coating 1 & Coating 2 & Coating 3 & Coating 4 & Coating 5 & Coating 6 \\
\hline $\begin{array}{l}\text { Sweetness } \\
\text { Color and }\end{array}$ & $08 \pm 0.1^{\mathrm{a}}$ & $06 \pm 0.1^{\mathrm{b}}$ & $06.5 \pm 0.3^{\mathrm{b}}$ & $08 \pm 0.5^{\mathrm{a}}$ & $07 \pm 0.5^{\mathrm{b}}$ & $07 \pm 0.5^{\mathrm{b}}$ & $07.5 \pm 0.5^{\mathrm{b}}$ \\
$\begin{array}{l}\text { appearance } \\
\begin{array}{l}\text { Body and } \\
\text { texture }\end{array}\end{array}$ & $08 \pm 0.3^{\mathrm{a}}$ & $06 \pm 0.2^{\mathrm{b}}$ & $06.5 \pm 0.8^{\mathrm{b}}$ & $07 \pm 0.5^{\mathrm{b}}$ & $07 \pm 0.7^{\mathrm{b}}$ & $07 \pm 0.6^{\mathrm{b}}$ & $07.0 \pm 0.4^{\mathrm{b}}$ \\
$\begin{array}{l}\text { Overall } \\
\text { acceptability }\end{array}$ & $08 \pm 0.7^{\mathrm{a}}$ & $07 \pm 0.6^{\mathrm{b}}$ & $07 \pm 0.5^{\mathrm{b}}$ & $07.5 \pm 0.4^{\mathrm{b}}$ & $07.5 \pm 0.2^{\mathrm{b}}$ & $07.5 \pm 0.1^{\mathrm{b}}$ & $07.5 \pm 0.8^{\mathrm{b}}$ \\
\hline
\end{tabular}

Note: Means in each row with different superscripts $(a, b)$ were significantly different (least significant difference test, $p<0.05)$ from each other. Data are presented as means \pm standard error mean $(n=6)$ 


\section{DISCUSSION}

There are several ways to analyze the sensory properties of chewing gum. The flavor of the gum changes slowly with time. The time intensity (T-I) method is often used to analyze the chewing gum characteristic. Mc Gowan et al (2005) investigated the potential use of corn zein in a chewing gum base. In those studies, formulations combining corn zein with different type of plasticizers were compared using T-I method for sensory evaluation. It was found that plasticizer not only affected the texture of the resulting gum but also their taste and aroma.

The firmness of coating 3 solutions was 0.990 $\mathrm{kg}$, which is similar to the firmness value obtained for the reference chewing gum. As the sweetener concentration increased, coating firmness also increased. During storage, the gum dries, water escapes first at the surface, and then over time the water in the core of the gum will migrate towards the surface to redistribute. Therefore, to prevent migration of water, immediately after formulation step the coating operation should be performed.

The results of the texture profile analysis provided potentially useful data on predicting the stability of the zein gum base texture. The physical parameters were similar to those of the reference chewing gum.

Adhesiveness is represented on TPA curve as negative force area under first compression cycle. Negative value indicates the work necessary to pull the probe from sticky zein gum interior. Adhesiveness is due to evaporation of ethanol during storage leaving behind increasingly polar medium that allowed hydrophobic interaction between zein molecule and promoted their self-assembly. As ethanol evaporated during storage, the mass consolidated in a sponge that allowed for development of adhesiveness, cohesiveness, and gumminess.

MCG-8 and MCG-2 with PEG-600 and PEG-200 as plasticizer had a biodegradation score of five, which indicates very low chalking, and thus reduced biodegradation. Results obtained by biodegradation data correspond well with TPA results. Decreased biodegradation score could be due to high hardness value of MCG-8. MCG-9 formulation with castor oil as plasticizer showed biodegradation score of one after weathering cycle, which indicates severe chalking on corn zein surface. Zein castor oil solvent systems are suspected of forming mesophases. Mesophase transformations accompanied by water migration during storage were believed to be responsible for gum structure changes, which lead to chalking at surface and subsequent biodegradation.

Among all the corn zein formulations, MCG-9 formulation with castor oil as plasticizer, showed highest drug release (95\%) after mean chewing time (30 $\mathrm{min}$ ), and showed uniform distribution of drug in gum matrix. A study by Kvist et al [14] on $20 \mathrm{mg}$ dimenhydrinate chewing gum showed about $90 \%$ release of dimenhydrinate from the synthetic gum base in $45 \mathrm{~min}$. Drug release from the chewing gum is dependent upon the water solubility of the drug. The more water-soluble the drug is, the more release from chewing gum occurs and vice versa. Drug release varied from $14-26 \%$ after $5 \mathrm{~min}, 39-51 \%$ after $15 \mathrm{~min}$ and $79-91 \%$ after 30 min for various corn zein chewing gum formulations. The difference in release may be linked to differences in sweetener content with different alcohol structure (sorbitol and mannitol). A study conducted by Aslani et al [16] on drug release of caffeine chewing gum showed that after 10, 20 and 30 min, drug release from synthetic gum base was 55,78 , and $89 \%$, respectively.

Overall acceptability score of corn zein chewing gum coated with coating 3 solutions was found to be similar with control containing sucrose. The higher score for appearance and texture in control corn zein chewing gum could be attributed to sucrose, because sucrose helps to form a network of microfibrils and create a binding effect in the product because of the humectant nature of sucrose and mannitol. Sucrose was used as control for the sensory evaluation and was assigned a sweetness per food energy value of one. Similarly, the higher score for color and appearance in control corn zein chewing gum may be attributed to browning reaction with sucrose. Hence, the overall acceptability of corn zein chewing gum sweetened with low calorie sweetener ranked slightly lower than for control. The results of the sensory evaluation show the possibility of using a low-calorie sweetener in corn zein chewing gum formulations.

\section{CONCLUSION}

Zein chewing gum has all the benefits of a synthetic chewing gum and can be used as a suitable drug delivery system. It has the advantage over synthetic gums in that it is biodegradable. The formulation containing castor oil as plasticizer (MCG-9) is the optimized formulation in terms of biodegradation. This formulation has a satisfactory release profile and 
is stable. Thus, the gum formulation is a potentially suitable delivery system for diphenhydramine for the treatment and/or prophylaxis of motion sickness.

\section{ACKNOWLEDGEMENT}

The authors wish to acknowledge C.S.I.R, New Delhi, India for providing SRF, and M.P.C.S.T Bhopal (M.P.) for funding the purchase of a texture analyzer.

\section{REFERENCES}

1. Shojaei A. Buccal mucosa as a route for systematic drug delivery. J Pharm Sci 1998; 1: 15-30.

2. Imfeld T. Chewing gum-facts and fiction: a review of gumchewing and oral health. Crit Rev Oral Biol M 1999; 10: 405-419.

3. Rassing MR. Chewing gum as drug delivery system. Adv Drug Deliv Rev 1994; 13: 89-121.

4. Mc Gowan AB, Pauda GW, Lee SY. Formulation of corn zein chewing gum and evaluation of sensory properties by the time intensity method. J Food Sci 2005; 70: 475-481.

5. Glasser GM. Moisture resistant coating for food products. Patent no EP 90559, Germany, 05/10/1983.

6. Haralampu SG, Sands S. Protein-based edible coatings. Patent no W01991006227 A1, USA, 16/05/1991.

7. Wasa T, Takahsahi J. Coating agent for food excellent in workability in coating. Patent no WO 1998014076 A1, USA, 09/04/1998.
8. Coleman RE. Zein solution and coating composition. Patent no US 2185110, USA, 26/12/1939.

9. Lai HM, Padua GW. Properties and microstructure of plasticized zein films. Cereal Chem. 1997; 74: 771775.

10. Avalle N. Cosmetic powders coated with natural ingredients. Patent no EP0882443 A2, Italy, 09/12/1998.

11. Zyck DJ, Greenberg MJ, Barkalow DG, Marske SW, Schnell PG, Mazzone P, Hammomd JE, Witkewitz $D L$, Sitler DJ,Petrocelli RM. Coated chewing gum product containing an antigas agent. Patent no US 6579545B2, USA, 17/06/2003.

12. Bourne MC. Texture profile analysis. Food Technol 1978; 32: $62-66$

13. Grawe $R$, Wimmer $T$. Degradable chewing gum bases and method of making. Patent no. US 7479293B2, USA, 20/01/2009.

14. Kvist $C$, Andersson SB, Fors $S$, Wennergren B, Berglund $J$. Apparatus for studying in vitro drug release from medicated chewing gums. Int J Pharm 1999; 189: 5765.

15. Arora $S$, Singh $V P$, Yarrakula $S$, Gawande $H$, Narendra K, Sharma V, Wadhwa BK, Tomer SK, Sharma GS. Textural and micro structural properties of burfi made with various sweeteners. J Food Sci 2007; 61(5): 1068-1072.

16. Aslani A, Jalilian F. Design, formulation and evaluation of caffeine chewing gum. Adv Biomed Res 2013; 2: 72. 